\title{
Exercise hemodynamics of bovine versus porcine bioprostheses: A prospective randomized comparison of the Mosaic and Perimount aortic valves
}

Walter B. Eichinger, MD, Florian Botzenhardt, MD, Alexandra Keithahn, Ralf Guenzinger, MD, Sabine Bleiziffer, MD, Ina Wagner, MD, Robert Bauernschmitt, MD, and Ruediger Lange, MD

See related editorial on page 961.
From the German Heart Center Munich, Department of Cardiovascular Surgery, Munich, Germany.

Received for publication May 21, 2004; revisions received July 30, 2004; accepted for publication Aug 18, 2004.

Address for reprints: Walter B. Eichinger, MD, Department of Cardiovascular Surgery, German Heart Center Munich, Lazarettstr 36, 80636 Munich, Germany (Email: eichinger@dhm.mhn.de).

J Thorac Cardiovasc Surg 2005;129: $1056-63$

$0022-5223 / \$ 30.00$

Copyright $\odot 2005$ by The American Association for Thoracic Surgery

doi:10.1016/j.jtcvs.2004.08.028
Objective: This prospective randomized study compares a porcine with a bovine bioprosthesis in the aortic position with regard to hemodynamic performance during exercise.

Methods: Between August of 2000 and December of 2002, 136 patients underwent aortic valve replacement with the porcine Medtronic Mosaic $(n=66)$ or the bovine Carpentier-Edwards Perimount $(n=70)$ bioprosthesis. Transthoracic echocardiography was performed to assess hemodynamic and dimensional data preoperatively and 10 months postoperatively; the latter follow-up included stress echocardiography with treadmill exercise.

Results: At rest and during exercise ( 25 and $50 \mathrm{~W}$ ), there was a significant difference in mean pressure gradient between the bovine and the porcine valves with labeled sizes 21 and 23, with superiority of the Perimount prosthesis. There was no difference in effective orifice area and incidence of patient-prosthesis mismatch among all sizes. The left ventricular mass index decreased significantly within 10 months postoperatively in the size 23 bovine group and the size 25 porcine group.

Conclusions: Our data show a significant superiority of pressure gradients for the bovine bioprosthesis, especially with small valve sizes, when compared with the porcine device, which is more distinctive during exercise.

$\mathrm{T}$ he major concern when implanting a biologic heart valve prosthesis are primary tissue failure after implantation and long-term hemodynamic performance. Most bioprostheses are made of either bovine pericardium or porcine heart valve tissue. Both types have been shown to warrant satisfactory hemodynamic results and tissue durability over 10 to 15 years. However, up to now, no prospective randomized comparison of both valve types under stress conditions has been available. Hence the aim of this study was to compare porcine and bovine bioprostheses in a prospective randomized investigational series with regard to differences in hemodynamic performance at rest and during exercise and postoperative left ventricular (LV) mass regression. The porcine valves are represented by the Medtronic Mosaic bioprosthesis (Medtronic, Inc, Minneapolis, Minn), and the bovine valves are represented by the Carpentier-Edwards Perimount bioprosthesis (Baxter Healthcare Corp, Edwards Division, Santa Ana, Calif).

\section{Methods}

\section{Patient Enrollment}

Between August of 2000 and September of 2002, 139 patients given a diagnosis of aortic stenosis or mixed lesion of the aortic valve required valve replacement and entered the study. Patients with isolated aortic regurgitation, patients who underwent replacement of more than one valve, or patients who already had a pre-existing prosthetic valve in another position were 
TABLE 1. Preoperative data

\begin{tabular}{lccc}
\hline & Mosaic & Perimount & $\boldsymbol{P}$ valuet \\
\hline No. of patients & 66 & 70 & \\
Age on implantation $(y)^{*}$ & & & \\
$\quad$ Mean & $76.1 \pm 5.3$ & $75.1 \pm 5.6$ & .293 \\
$\quad$ Range & $65.7-89.5$ & $60.1-87.8$ & \\
Sex & & & .524 \\
$\quad$ Male & 30 & 28 & \\
Female & 36 & 42 & \\
Body surface area $\left(\mathrm{m}^{2}\right)^{*}$ & $1.81 \pm 0.19$ & $1.81 \pm 0.21$ & .922 \\
Cardiac rhythm & & & \\
$\quad$ Sinus rhythm & 56 & 52 & \\
Atrial fibrillation & 7 & 10 & \\
Heart block & 2 & 2 & \\
Paced rhythm & 1 & 6 & \\
NYHA classification & & & \\
Class I & 0 & 0 & \\
Class II & 3 & 5 & \\
Class III & 53 & 49 & \\
Class IV & 10 & 16 & \\
Aortic valve lesion & & & \\
Isolated stenosis & 26 & 31 & \\
Stenosis and & 40 & 39 & \\
$\quad$ regurgitation & & & \\
Left ventricular mass & $184.5 \pm 70.9$ & $179.9 \pm 68.5$ & \\
index (g/m ${ }^{*}$ & & & \\
\hline
\end{tabular}

NYHA, New York Heart Association. *Results as means \pm SD. $\dagger t$ Test for independent samples.

excluded from enrollment. Patients undergoing other concomitant procedures were permitted to enter the study. Preoperative randomization was performed after each patient's informed consent was received by blindly choosing a closed envelope, which contained a note for one of the valves studied. Thus, the patients either received the Medtronic Mosaic $(n=66$; mean age at implantation, 76.1 years; $45.5 \%$ male subjects) or the Edwards Perimount $(\mathrm{n}=$ 70; mean age at implantation, 75.1 years; $40.0 \%$ male subjects) bioprosthesis. The study was approved by the institutional ethics committee. Preoperative and operative data of each group are summarized in Tables 1 and 2. In $t$ tests for independent samples, the porcine and bovine groups did not differ significantly with regard to sex, age, distribution of preoperative New York Heart Association class, heart rhythm, aortic valve lesion, LV morphology and function (Table 3), aortic crossclamp time, and valve size distribution. The patients were examined preoperatively and 10 months (mean, $9.2 \pm 5.2$ months) postoperatively, with the latter investigation including transthoracic echocardiography at rest and at stress by using treadmill exercise.

\section{Exercise Protocol}

During bicycle exercise, patients sat on a seat reclined in a $50^{\circ}$ position. The starting workload was $0 \mathrm{~W}$ and was then increased by $25 \mathrm{~W}$ every 2 minutes. The patients were encouraged to exercise until exhaustion. The test was stopped if there was no increase or an abnormal increase in blood pressure (diastolic blood pressure, $>110 \mathrm{~mm} \mathrm{Hg}$ ), electrocardiographic evidence of isch-
TABLE 2. Operative data

\begin{tabular}{lccc}
\hline & Mosaic & Perimount & $\boldsymbol{P}$ valuet \\
\hline Valve size (labeled) & & & \\
19 & 3 & 5 & \\
21 & 20 & 25 & \\
23 & 30 & 32 & \\
25 & 13 & 8 & \\
Average* & $22.6 \pm 1.6$ & $22.2 \pm 1.6$ & .170 \\
Valve size index (mm/m ${ }^{2}{ }^{*}$ & $12.6 \pm 1.2$ & $12.4 \pm 1.3$ & .447 \\
Aortic annulus diameter & $22.6 \pm 1.8$ & $22.6 \pm 1.7$ & .831 \\
Concomitant procedures & & & \\
$\quad$ None & 33 & 35 & \\
CABG & 30 & 33 & \\
$\quad$ Other & 3 & 2 & \\
Aortic crossclamp time (min) & & & \\
$\quad$ Isolated procedures & $61.2 \pm 15.2$ & $62.0 \pm 14.8$ & .866 \\
Combined procedures & $81.7 \pm 19.1$ & $89.3 \pm 26.1$ & .265
\end{tabular}

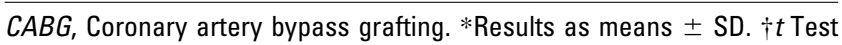
for independent samples.

emia (horizontal or downsloping S-T depression or S-T lifting), significant arrhythmia (new atrial fibrillation or ventricular arrhythmia), chest pain, vertigo, inadequate tachycardia, or inadequate dyspnea. To facilitate Doppler measurements during exercise, the site on the chest where optimum Doppler wave forms had been recorded was marked before starting exercise. In case of unsatisfactory Doppler signals, the whole bicycle unit was tilted slightly to the left side until optimal measurements were obtained. Measurements were performed at the end of each 2-minute workload level. Blood pressure was measured noninvasively every minute with a sphygmomanometer cuff fixed on the right arm. A 12-lead electrocardiogram was continuously recorded.

\section{Echocardiographic Measurement}

Echocardiographic measurements performed at rest included the transvalvular flow velocity with continuous-wave Doppler scanning and left ventricular outflow tract (LVOT) flow velocity with

TABLE 3. Left ventricular morphology and function at late follow-up

\begin{tabular}{lccc}
\hline & Mosaic & Perimount & $P$ value* \\
\hline $\begin{array}{l}\text { End-diastolic dimension } \\
\quad(\mathrm{mm})\end{array}$ & $44.6 \pm 7.0$ & $44.5 \pm 10.0$ & .944 \\
$\begin{array}{l}\text { End-systolic dimension } \\
\quad(\mathrm{mm})\end{array}$ & $33.6 \pm 8.2$ & $33.3 \pm 9.7$ & .843 \\
$\begin{array}{l}\text { End-diastolic septum } \\
\quad \text { thickness (mm) }\end{array}$ & $11.4 \pm 2.9$ & $11.9 \pm 2.2$ & .402 \\
$\begin{array}{l}\text { End-diastolic posterior } \\
\quad \text { wall thickness (mm) }\end{array}$ & $12.4 \pm 2.3$ & $11.9 \pm 2.4$ & .278 \\
$\begin{array}{l}\text { Left ventricular mass (g) } \\
\text { Left ventricular mass } \\
\quad \text { index (g/m }\end{array}$ & $256.0 \pm 107.4$ & $250.7 \pm 99.9$ & .803 \\
& $142.1 \pm 55.8$ & $136.2 \pm 50.1$ & .592 \\
Fractional shortening (\%) & $24.9 \pm 11.1$ & $25.8 \pm 9.7$ & .696 \\
\hline
\end{tabular}

Results are presented as means \pm SD. $* t$ Test for independent samples. 
TABLE 4, A. Hemodynamic results at rest grouped by labeled valve size

\begin{tabular}{|c|c|c|c|c|c|}
\hline \multirow[b]{2}{*}{ Parameter } & \multicolumn{5}{|c|}{ Valve size } \\
\hline & All & 19 & 21 & 23 & 25 \\
\hline \multicolumn{6}{|c|}{ Mean pressure gradient $(\mathrm{mm} \mathrm{Hg})$} \\
\hline Mosaic & $14.6 \pm 5.0^{*}$ & $26.2 \pm 8.0$ & $14.9 \pm 4.5^{*}$ & $13.8 \pm 4.4^{*}$ & $13.7 \pm 4.0$ \\
\hline Perimount & $11.4 \pm 4.1^{*}$ & $17.9 \pm 3.7$ & $11.2 \pm 3.5^{*}$ & $10.9 \pm 4.3^{*}$ & $10.6 \pm 2.1$ \\
\hline \multicolumn{6}{|c|}{ Effective orifice area $\left(\mathrm{cm}^{2}\right)$} \\
\hline Mosaic & $1.49 \pm 0.52$ & $0.74 \pm 0.30$ & $1.18 \pm 0.27$ & $1.54 \pm 0.52$ & $1.94 \pm 0.43$ \\
\hline Perimount & $1.56 \pm 0.41$ & $0.92 \pm 0.04$ & $1.39 \pm 0.39$ & $1.71 \pm 0.34$ & $1.76 \pm 0.40$ \\
\hline \multicolumn{6}{|c|}{ Effective orifice area index $\left(\mathrm{cm}^{2} / \mathrm{m}^{2}\right)$} \\
\hline Mosaic & $0.84 \pm 0.31$ & $0.45 \pm 0.16$ & $0.68 \pm 0.17$ & $0.88 \pm 0.33$ & $1.04 \pm 0.30$ \\
\hline Perimount & $0.86 \pm 0.24$ & $0.58 \pm 0.05$ & $0.81 \pm 0.25$ & $0.91 \pm 0.22$ & $0.92 \pm 0.27$ \\
\hline
\end{tabular}

Results are presented as means $\pm \mathrm{SD}$. $* P<.05, t$ test for independent samples.

pulsed-wave Doppler scanning. LVOT diameter was assessed from a parasternal long-axis view. The same measurements were performed during exercise, except for LVOT diameter, which was assumed to remain constant. ${ }^{1}$ The velocity recording was first performed in the transvalvular jet and then in the LVOT. From these measurements, we calculated the LV stroke volume as the product of LVOT velocity time integral and cross-sectional area and the cardiac output as the product of stroke volume and heart rate. The transvalvular pressure gradient was calculated by using the modified Bernoulli equation, with inclusion of subvalvular velocity and the effective orifice area (EOA) by using the standard continuity equation. If the difference in heart rate between the time of transvalvular velocity recording and that of LVOT velocity recording was greater than $5 \%$, the data were rejected to avoid potential errors in EOA and mean gradient because of changing hemodynamics. The EOA was indexed for body surface area.

LV end-systolic and end-diastolic dimensions and the thickness of the LV posterior wall and interventricular septum were assessed in the short axis of the parasternal view by means of multiple M-mode measurements with calculation of shortening fraction. LV mass was calculated by using the corrected formula of the American Society of Echocardiography and was indexed by body surface area. $^{2}$

\section{Implanted Porcine and Bovine Bioprostheses}

The Medtronic Mosaic is a stented heart valve fixed with glutaraldehyde at zero pressure and treated with $\alpha$-amino-oleic acid to reduce tissue calcification. It has been in clinical use since 1994 (Europe) and 2000 (United States), respectively, and has shown satisfactory hemodynamic performance and freedom rates from adverse events. ${ }^{3-6}$ The Carpentier-Edwards Perimount is also a stented heart valve fixed with glutaraldehyde at low pressure, and the cusps are treated with surfactant to restrict calcification. The Perimount received US Food and Drug Administration approval in 1991. Long-term studies have constantly shown excellent hemodynamic and clinical results. ${ }^{7-10}$

\section{Surgical Procedure}

Aortic valve replacement was undertaken by using standard cardiopulmonary bypass at mild hypothermia with cold crystalloid cardioplegia. Intraoperatively, aortic annulus diameter was measured by the surgeon by inserting a Hegar dilator into the annulus. Mean aortic annulus diameter was equal in the Mosaic and the Perimount groups. Prosthetic valve size was determined by using the original sizer provided by each manufacturer. The Mosaic valve is designed to allow for a complete supra-annular implantation technique made possible by a low-profile stent design and a

TABLE 4, B. Hemodynamic results at rest grouped by aortic annulus diameter

\begin{tabular}{|c|c|c|c|c|}
\hline \multirow[b]{2}{*}{ Parameter } & \multicolumn{4}{|c|}{ Aortic annulus diameter (mm) } \\
\hline & $18-20$ & $21-22$ & $23-24$ & $25-26$ \\
\hline \multicolumn{5}{|c|}{ Mean pressure gradient $(\mathrm{mm} \mathrm{Hg})$} \\
\hline Mosaic & $19.2 \pm 7.6$ & $14.9 \pm 4.9^{*}$ & $13.3 \pm 3.9$ & $13.5 \pm 4.2$ \\
\hline Perimount & $17.6 \pm 3.1$ & $10.7 \pm 3.0^{*}$ & $10.9 \pm 4.5$ & $10.6 \pm 2.1$ \\
\hline \multicolumn{5}{|c|}{ Effective orifice area $\left(\mathrm{cm}^{2}\right)$} \\
\hline Mosaic & $0.89 \pm 0.22$ & $1.36 \pm 0.39$ & $1.59 \pm 0.54$ & $1.95 \pm 0.45$ \\
\hline Perimount & $0.93 \pm 0.04$ & $1.47 \pm 0.39$ & $1.70 \pm 0.34$ & $1.76 \pm 0.40$ \\
\hline \multicolumn{5}{|c|}{ Effective orifice area index $\left(\mathrm{cm}^{2} / \mathrm{m}^{2}\right)$} \\
\hline Mosaic & $0.53 \pm 0.14$ & $0.77 \pm 0.23$ & $0.90 \pm 0.36$ & $1.06 \pm 0.32$ \\
\hline Perimount & $0.57 \pm 0.04$ & $0.84 \pm 0.25$ & $0.91 \pm 0.22$ & $0.92 \pm 0.27$ \\
\hline
\end{tabular}

Results are presented as means $\pm \mathrm{SD}$. $* P<.05, t$ test for independent samples. 
TABLE 5, A. Hemodynamic results at stress grouped by labeled valve size

\begin{tabular}{|c|c|c|c|c|c|c|c|c|c|}
\hline \multirow[b]{2}{*}{ Size } & \multirow[b]{2}{*}{ Valve } & \multicolumn{2}{|c|}{ Rest } & \multicolumn{2}{|c|}{$25 \mathrm{~W}$} & \multicolumn{2}{|c|}{$50 \mathrm{~W}$} & \multicolumn{2}{|c|}{$75 \mathrm{~W}$} \\
\hline & & MPG & SV & MPG & SV & MPG & SV & MPG & SV \\
\hline \multirow[t]{2}{*}{ All } & Mosaic & $14.6 \pm 5.0^{*}$ & $83.1 \pm 23.3$ & $18.2 \pm 5.8^{*}$ & $84.3 \pm 20.1$ & $21.8 \pm 5.6^{*}$ & $97.8 \pm 20.4$ & $23.7 \pm 6.7$ & $119.1 \pm 34.3^{*}$ \\
\hline & Perimount & $11.4 \pm 4.1^{*}$ & $79.5 \pm 21.1$ & $13.4 \pm 3.6^{*}$ & $79.6 \pm 17.8$ & $16.5 \pm 4.0^{*}$ & $86.6 \pm 17.7$ & $20.1 \pm 5.9$ & $99.1 \pm 19.6^{*}$ \\
\hline \multirow[t]{2}{*}{19} & Mosaic & $26.2 \pm 8.0$ & $54.8 \pm 15.0$ & $28.4 \pm 9.0$ & $56.0 \pm 17.4$ & 18.8 & 72.5 & - & - \\
\hline & Perimount & $17.9 \pm 3.7$ & $62.3 \pm 14.8$ & $20.7 \pm 4.4$ & $68.2 \pm 20.6$ & $26.4 \pm 2.4$ & $63.5 \pm 14.4$ & - & - \\
\hline \multirow[t]{2}{*}{21} & Mosaic & $14.9 \pm 4.5^{*}$ & $71.4 \pm 14.8$ & $19.4 \pm 6.4^{*}$ & $76.5 \pm 18.3$ & $22.5 \pm 6.0^{*}$ & $87.5 \pm 19.4$ & 25.1 & 120.1 \\
\hline & Perimount & $11.2 \pm 3.5^{*}$ & $70.8 \pm 21.3$ & $12.5 \pm 1.9^{*}$ & $67.4 \pm 12.4$ & $15.4 \pm 2.2^{*}$ & $79.2 \pm 11.7$ & $17.4 \pm 3.5$ & $77.8 \pm 15.6$ \\
\hline \multirow[t]{2}{*}{23} & Mosaic & $13.8 \pm 4.4^{*}$ & $85.4 \pm 23.2$ & $17.1 \pm 4.7^{*}$ & $87.0 \pm 18.8$ & $22.6 \pm 5.4^{*}$ & $99.9 \pm 19.5$ & $25.7 \pm 5.6$ & $110.4 \pm 33.9$ \\
\hline & Perimount & $10.9 \pm 4.3^{*}$ & $88.7 \pm 20.1$ & $13.2 \pm 3.5^{*}$ & $86.0 \pm 16.7$ & $17.0 \pm 3.6^{*}$ & $91.9 \pm 19.1$ & $22.1 \pm 6.5$ & $103.9 \pm 20.4$ \\
\hline \multirow[t]{2}{*}{25} & Mosaic & $13.7 \pm 4.0$ & $99.1 \pm 23.2^{*}$ & $17.1 \pm 5.3$ & $94.2 \pm 19.1$ & $19.6 \pm 5.8$ & $108.5 \pm 18.3$ & $20.2 \pm 8.0$ & $133.5 \pm 35.9$ \\
\hline & Perimount & $10.6 \pm 2.1$ & $73.1 \pm 9.0^{*}$ & $13.0 \pm 2.9$ & $92.2 \pm 13.7$ & $13.7 \pm 3.8$ & $95.8 \pm 14.8$ & $17.5 \pm 4.8$ & $104.1 \pm 10.1$ \\
\hline
\end{tabular}

Results are presented as means $\pm \mathrm{SD}$. $M P G$, Mean pressure gradient; $S V$, stroke volume. $* P<.05, t$ test for independent samples.

construction involving no stent material reaching into the aortic annulus and disturbing the physiologic flow pattern. The Perimount bioprosthesis is sized for and implanted in the intra-supraannular position. There was no difference in the operative technique between both valve types. The bioprostheses were implanted with pledget-supported, interrupted, noneverting mattress sutures.

\section{Statistical Analysis}

Data are expressed as means $\pm 1 \mathrm{SD}$. Comparisons between both groups were made by the $t$ test for independent samples in case of normal data distribution and the Mann-Whitney $U$ test in case of nonnormal data distribution. Comparisons within one group were performed by using the $t$ test for dependent samples or the Wilcoxon matched pairs test, respectively. Correlations were tested with the Pearson product-moment method. Because there were few patients in the size 19 groups, no statistical comparison was performed for this group.

\section{Results}

\section{Hemodynamic Results at Rest}

Mean systolic pressure gradient, EOA, and effective orifice area index (EOAI) of the Mosaic and the Perimount valves after $9.2 \pm 5.2$ months at rest are depicted in Table 4, A, grouped by labeled valve size and in Table $4, B$, grouped by aortic annulus diameter.

\section{Hemodynamic Results at Stress}

Mean systolic pressure gradients during treadmill exercise are depicted in Table $5, A$, grouped by labeled valve size and by exercise level and in Table $5, B$, grouped by aortic annulus diameter. Additionally, the corresponding mean stroke volume of each subgroup is shown to refer potential differences in mean pressure gradient to differences in volume load. Exercise data are complete for 46 patients in the Perimount group and 47 patients in the Mosaic group. Five patients died before late follow-up, with death unrelated to the valves studied (Perimount, $\mathrm{n}$ $=3$; Mosaic, $\mathrm{n}=2$ ). Of the remaining 38 patients, 15 patients did not attend the follow-up examination because of general morbidity. Data of 23 patients obtained during exercise were excluded from statistical calculations because suboptimal sonic conditions did not allow reliable echocardiographic measurements.

TABLE 5, B. Hemodynamic results at stress grouped by aortic annulus diameter

\begin{tabular}{|c|c|c|c|c|c|c|c|}
\hline \multirow{2}{*}{$\begin{array}{c}\text { Aortic } \\
\text { annulus }\end{array}$} & \multirow[b]{2}{*}{ Valve } & \multicolumn{2}{|c|}{$25 \mathrm{~W}$} & \multicolumn{2}{|c|}{$50 \mathrm{~W}$} & \multicolumn{2}{|c|}{$75 \mathrm{~W}$} \\
\hline & & MPG & SV & MPG & SV & MPG & SV \\
\hline \multirow[t]{2}{*}{$18-20$} & Mosaic & $22.0 \pm 7.4$ & $67.3 \pm 16.2$ & $20.6 \pm 2.5$ & $85.4 \pm 12.6$ & - & - \\
\hline & Perimount & $18.5 \pm 5.6$ & $70.4 \pm 17.3$ & $22.9 \pm 6.3$ & $68.9 \pm 13.8$ & 20.8 & 83.0 \\
\hline \multirow[t]{2}{*}{$21-22$} & Mosaic & $19.3 \pm 6.4^{*}$ & $84.0 \pm 21.9^{*}$ & $23.7 \pm 6.3^{*}$ & $95.5 \pm 23.4$ & $28.5 \pm 3.0^{*}$ & $129.2 \pm 30.7$ \\
\hline & Perimount & $12.8 \pm 2.2^{*}$ & $69.7 \pm 14.2^{*}$ & $15.4 \pm 2.2^{*}$ & $81.7 \pm 13.0$ & $16.5 \pm 2.4^{*}$ & $88.3 \pm 27.2$ \\
\hline \multirow[t]{2}{*}{$23-24$} & Mosaic & $16.1 \pm 3.9^{*}$ & $84.2 \pm 15.7$ & $20.6 \pm 4.5^{*}$ & $97.7 \pm 16.9$ & $23.3 \pm 5.8$ & $96.3 \pm 27.2$ \\
\hline & Perimount & $13.0 \pm 3.6^{*}$ & $85.7 \pm 17.4$ & $17.1 \pm 3.7^{*}$ & $91.3 \pm 20.1$ & $22.6 \pm 6.8$ & $102.6 \pm 21.3$ \\
\hline \multirow[t]{2}{*}{$25-26$} & Mosaic & $17.2 \pm 5.6$ & $94.7 \pm 20.2$ & $19.9 \pm 6.0$ & $108.0 \pm 19.3$ & $20.2 \pm 8.0$ & $133.5 \pm 35.9$ \\
\hline & Perimount & $13.0 \pm 2.9$ & $92.2 \pm 13.7$ & $13.7 \pm 3.8$ & $95.8 \pm 14.8$ & $17.5 \pm 4.8$ & $104.1 \pm 10.1$ \\
\hline
\end{tabular}

Results are presented as means $\pm \mathrm{SD}$. $M P G$, Mean pressure gradient; $S V$, stroke volume. $* P<.05, t$ test for independent samples. 
TABLE 6. Incidence of patient-prosthesis mismatch grouped by labeled valve size

\begin{tabular}{llccc}
\hline & & \multicolumn{3}{c}{ Patient-prosthesis mismatch } \\
\cline { 3 - 5 } Size & Valve & $\begin{array}{c}\text { No } \\
\text { (EOAI }>\mathbf{0 . 8 5} \\
\mathbf{c m}^{2} / \mathbf{m}^{2} \text { ) }\end{array}$ & $\begin{array}{c}\text { Moderate } \\
\text { (EOA) } \leq \mathbf{0 . 8 5} \\
\mathbf{c m}^{2} / \mathbf{m}^{2} \text { ) }\end{array}$ & $\begin{array}{c}\text { Severe } \\
\text { (EOAI } \leq \mathbf{0 . 6 5} \\
\mathbf{c m}^{2} / \mathbf{m}^{2} \text { ) }\end{array}$ \\
\hline \multirow{2}{*}{19} & Mosaic & $0 \%$ & $0 \%$ & $100 \%$ \\
& Perimount & $0 \%$ & $0 \%$ & $100 \%$ \\
21 & Mosaic & $15.4 \%$ & $38.5 \%$ & $46.2 \%$ \\
& Perimount & $40.0 \%$ & $20.0 \%$ & $40.0 \%$ \\
23 & Mosaic & $40.9 \%$ & $36.4 \%$ & $22.7 \%$ \\
& Perimount & $56.5 \%$ & $30.4 \%$ & $13.0 \%$ \\
& Mosaic & $70.0 \%$ & $20.0 \%$ & $10.0 \%$ \\
& Perimount & $60.0 \%$ & $20.0 \%$ & $20.0 \%$ \\
\hline
\end{tabular}

EOAl, Effective orifice area index.

\section{Patient-Prosthesis Mismatch}

Patient-prosthesis mismatch is rated in 3 grades according to the results in EOAI: no mismatch, EOAI greater than $0.85 \mathrm{~cm}^{2} / \mathrm{m}^{2}$; moderate mismatch, EOAI less than or equal to $0.85 \mathrm{~cm}^{2} / \mathrm{m}^{2}$; and severe mismatch, EOAI less than or equal to $0.65 \mathrm{~cm}^{2} / \mathrm{m}^{2}{ }^{11}$ The incidence of patient-prosthesis mismatch grouped by labeled valve size is shown in Table 6.

\section{Left Ventricular Mass Regression}

LV mass regression between preoperative echocardiographic measurement and late follow-up (9.2 \pm 5.2 months) is shown in Table 7 represented by the change in LV mass index.

\section{Discussion}

Heart valve bioprostheses do not require constant anticoagulant therapy because of lower thrombogenicity compared with mechanical prostheses. However, the use of bioprosthetic valves for heart valve replacement is restricted be- cause of the limited tissue durability. About 8 years after implantation, bovine and porcine valves exhibit a clear progression in the frequency of structural valve deterioration. ${ }^{12,13}$ Therefore, bioprostheses are mostly implanted in patients older than 70 years of age, assuming that the patient's death precedes prosthetic failure. Within the group of biologic heart valves, the most frequently used valves consist of porcine heart valve tissue or of bovine pericardial tissue. Both for the porcine and for the bovine bioprostheses, various investigational series have demonstrated satisfactory hemodynamic and clinical performance. In particular, the analyzed devices of this study (Mosaic and Perimount) have shown low mean pressure gradients, large effective orifice areas, and high freedom rates from prosthesis-related adverse events in long-term studies. ${ }^{3-10}$ However, up to now, there has been no direct comparison between porcine and bovine bioprostheses within a prospective randomized study design to analyze the hemodynamic performance of both groups at rest and during exercise. Obviously, results obtained at stress are by far more suitable to investigate the performance of a valve type than hemodynamic data obtained at rest.

\section{Hemodynamic Data at Rest and at Stress}

No statistical comparison was performed in the size 19 group because of the small number of patients enrolled. Concerning the hemodynamic results at rest, there is a significant superiority in mean pressure gradient of the bovine bioprosthesis in general $(P=.001)$ with valve sizes $21(P=.022)$ and $23(P=.031)$ compared with the porcine valve sizes 21 and 23 . No significant difference was found in mean pressure gradient comparing valve size $25(P=$ .139), but an obvious trend toward lower pressure gradients was seen in the bovine group. However, Vitale and colleagues ${ }^{14}$ and Bortolotti and associates ${ }^{15}$ reported on higher pressure gradients with the size 19 and 21 Perimount valves.

TABLE 7. Postoperative left ventricular mass regression grouped by labeled valve size

\begin{tabular}{llccr}
\hline & & \multicolumn{3}{c}{ Left ventricular mass index $\left(\mathbf{g} / \mathbf{m}^{2}\right)$} \\
\cline { 3 - 5 } Size & Valve & Preoperative & Postoperative & Reduction \\
\hline All & Mosaic & $187.2 \pm 69.4^{*}$ & $139.1 \pm 56.7^{*}$ & $-48.0 \pm 88.9$ \\
& Perimount & $175.8 \pm 52.7^{*}$ & $134.1 \pm 49.5^{*}$ & $-41.8 \pm 67.2$ \\
19 & Mosaic & $233 \pm 63.3$ & $131 \pm 6.1$ & $-98.6 \pm 57.2$ \\
& Perimount & $151.7 \pm 66.3$ & $136.8 \pm 25.2$ & $-15.0 \pm 49.7$ \\
21 & Mosaic & $179.6 \pm 48.4$ & $151.5 \pm 56.2$ & $-28.2 \pm 69.9$ \\
& Perimount & $192.7 \pm 71.0$ & $139.6 \pm 68.4$ & $-53.2 \pm 92.1$ \\
23 & Mosaic & $185.7 \pm 78.9$ & $142.0 \pm 67.8$ & $-43.7 \pm 104.5$ \\
& Perimount & $171.2 \pm 39.8^{*}$ & $131.2 \pm 41.2^{*}$ & $-39.9 \pm 57.8$ \\
& Mosaic & $190.8 \pm 77.2^{*}$ & $117.2 \pm 25.4^{*}$ & $-73.6 \pm 77.7$ \\
\end{tabular}

Results are presented as means \pm SD. 
During exercise, the size 21 and 23 bovine prostheses again showed significantly lower mean pressure gradients than the porcine valves, with even more distinct differences (size $21, P=.0006$ in $25 \mathrm{~W}$ and $P=.0005$ in $50 \mathrm{~W}$; size $23, P=.002$ in $25 \mathrm{~W}$ and $P=.0007$ in $50 \mathrm{~W}$ ). In the size 19 and 25 groups, there is a trend towards better hemodynamics in the bovine group but without significant results in $t$ tests for independent samples for the size 25 group ( $P=$ .132 in $25 \mathrm{~W}$ and $P=.061$ in $50 \mathrm{~W}$ ).

Mean pressure gradient was calculated according to the modified Bernoulli formula, which is based on the blood flow velocity measured by means of continuous Doppler scanning at the prosthesis and by means of pulsed Doppler scanning in the LVOT. To exclude differences in mean pressure gradient between both investigated bioprostheses caused by different levels of blood flow at the same level of exercise, we added the mean stroke volume for each valve size at each exercise level to the table of results. As depicted in Table 4, there was no significant difference in the mean stroke volume of the size 21 and 23 prostheses, which differed significantly in mean pressure gradients. We preferred to refer the hemodynamic results at stress to the stroke volume to omit bias caused by interindividual performance levels during exercise. However, often cardiac output (stroke volume $\times$ heart rate in milliliters per minute) is used as a reference. We observed that old patients, in particular, often increase their cardiac output, mainly by an increase in heart rate and not by enhancing the stroke volume. Finally, cardiac output increases during exercise, with steady stroke volume. We think that the stroke volume is the decisive parameter, which mainly influences the pressure gradients, and therefore, the stroke volume is the most suitable parameter as a reference value for comparisons of hemodynamic data at stress.

It should be mentioned that the comparison of 2 bioprostheses according to their labeled valve size is difficult because the labeled valve size does not represent the geometric dimensions of the valve. In general, the inner diameter of the Mosaic prosthesis is smaller across all sizes than the inner diameter of the Perimount prosthesis, whereas the sewing ring diameter of the Mosaic valve is smaller in sizes 19, 21, and 23; equal in size 25; and larger in sizes 27 and 29 in comparison with that of the Perimount valve. Moreover, the Mosaic is intended for complete supra-annular position and the Perimount for intra-supra-annular position. For example, in the same aortic root either a size 21 Perimount or a size 23 Mosaic prosthesis, allowing for lower pressure gradients, might be implanted. However, this upsizing is not considered in a hemodynamic comparison simply on the basis of labeled valve size. Such difficulties must be considered when assessing the hemodynamic performance of these prostheses and additionally must be re- membered in all comparisons between different heart valve prostheses. ${ }^{16}$

For this reason, the hemodynamic results are additionally depicted according to the patient annulus diameter, which was measured intraoperatively by the cardiac surgeon (Tables $4, B$, and $5, B$ ). In this series the mean aortic annulus diameter was identical for the Mosaic and the Perimount groups $(22.6 \mathrm{~mm})$. The mean labeled valve size did not differ significantly (Mosaic, $22.6 \mathrm{~mm}$; Perimount, 22.2 $\mathrm{mm}$ ), with a tendency toward larger valve sizes in patients receiving Mosaic prostheses. These results do not confirm the expectation that in general a Mosaic prosthesis larger in labeled valve size can be implanted than a Perimount prosthesis. The fact that upsizing of the Mosaic valve is not possible in all cases can be explained by looking at the geometric dimensions of both prostheses. The sewing ring diameter of the size 23 Perimount prostheses is $31 \mathrm{~mm}$, the sewing ring diameter of a size 23 Mosaic prosthesis is 30 $\mathrm{mm}$, and the sewing ring diameter of a size 25 Mosaic prosthesis is $33 \mathrm{~mm}$. Therefore, an objective comparison of the hemodynamic results between different prostheses should be based on the patient's aortic annulus diameter measured intraoperatively with a neutral instrument, such as a Hegar dilator. Regarding all patients, there is a significant superiority in mean pressure gradient of the Perimount prosthesis at rest $(P=.001)$, which becomes even more distinct during exercise $(P<.001$ at $25 \mathrm{~W}$ and $P<.0001$ at $50 \mathrm{~W}$ ).

\section{Patient-Prosthesis Mismatch}

Regarding EOA and EOAI, there is no significant difference between both valve types. EOAI is an important variable because it includes EOA, representing the prosthetic hemodynamic performance and body surface area as an indicator of the patient's estimated need for performance. EOAI is the decisive parameter to describe the incidence of patientprosthesis mismatch. We rated the extent of patient-prosthesis mismatch as not present in patients with an EOAI of greater than $0.85 \mathrm{~cm}^{2} / \mathrm{m}^{2}$, moderate in patients with an EOAI of $0.85 \mathrm{~cm}^{2} / \mathrm{m}^{2}$ or less, and severe in patients with an EOAI of $0.65 \mathrm{~cm}^{2} / \mathrm{m}^{2}$ or less. ${ }^{11}$ This graduation corresponds to the general concept that moderate aortic stenosis of a native valve is present in patients with an EOAI of less than $0.90 \mathrm{~cm}^{2} / \mathrm{m}^{2} .{ }^{17}$ Although the aim of aortic valve replacement in patients with aortic stenosis is to remove the stenosis and to realize nearly physiologic transvalvular gradients, a residual stenosis represented by low EOAI is frequent, especially with small valve sizes. Patient-prosthesis mismatch is present in up to $52 \%$ of the patients with a stented aortic bioprosthesis. ${ }^{18}$ This corresponds to the incidence of patient-prosthesis mismatch seen in this series with valve sizes 23 and 25 . Because patient-prosthesis mismatch might be associated with higher pressure gradients, less LV 
mass regression, and increased morbidity and mortality, ${ }^{19-21}$ various strategies to reduce the incidence of mismatch were introduced: aortic root enlargement, stentless bioprostheses, and full root replacement. The application of aortic root enlargement procedures must be recommended, especially for patients with an aortic annulus that would only allow the implantation of a size 19 valve. In this series there is a mismatch in $100 \%$ of the patients with a size 19 valve. Thus, neither a bovine nor porcine stented bioprosthesis of size 19 can be recommended for implantation, apart from patients with increased risk for aortic root enlargement or with such a small body surface area that mismatch does not occur.

\section{Left Ventricular Mass Regression}

All patients in our series showed a regression in LV mass and mass index, irrespective of prosthesis size, although a significance in $t$ test results was only seen with the size 23 bovine and the size 25 porcine valves. There was no significant difference between both valve types regarding the absolute amount of LV mass regression. Although there was a clear reduction in $\mathrm{LV}$ mass, the average postoperative $\mathrm{LV}$ mass index for the entire series remained greater than normal in $34.9 \%$ of the patients, with LV hypertrophy defined as an LV mass index of greater than $130 \mathrm{~g} / \mathrm{m}^{2}$ in male subjects and greater than $100 \mathrm{~g} / \mathrm{m}^{2}$ in female subjects. ${ }^{22}$ Similar observations have been made in other studies of various heart valve devices. ${ }^{23-25}$ The reasons for incomplete regression of hypertrophy include a residual aortic gradient caused by patient-prosthesis mismatch, persistent high blood pressure, and nonhemodynamic factors, such as genotype. $^{25}$ Preoperative LV mass in patients with aortic stenosis is markedly increased. The magnitude of absolute $\mathrm{LV}$ mass index regression is closely related to preoperative LV mass index. ${ }^{26}$ In our series the correlation between preoperative LV mass index and postoperative LV mass reduction was an $r$ value of $-0.74\left(r^{2}=0.55, P<.01\right)$.

\section{Conclusions}

Both the porcine and the bovine prostheses showed satisfactory hemodynamic results at rest and during exercise. The bovine bioprosthesis was significantly superior when mean pressure gradients were compared in small valve sizes (21 and $23 \mathrm{~mm}$ ), and this difference was even more obvious during exercise at 25 and $50 \mathrm{~W}$. However, geometric differences have to be considered between both prostheses, with the Mosaic prosthesis being generally smaller than the Perimount prosthesis. Nevertheless, when summarizing all valve sizes, the aortic annulus diameter was equal in both groups, and the pressure gradients were significantly lower in the bovine group.

We recommend that the pressure gradients obtained during stress echocardiography be referred to the stroke volume instead of cardiac output because cardiac output is strongly influenced by increasing heart rate in elderly patients during exercise.

Patient-prosthesis mismatch is a common complication in aortic valve replacement with small valve sizes. This experience was confirmed in this series without significant differences between both valve types. Mismatch was present in $100 \%$ of the patients with valve size 19 , and thus aortic root enlargement procedures and implantation of a larger valve should be recommended instead of implantation of a valve labeled size 19 .

\section{References}

1. Rassi A, Crawford MH, Richards KL, Miller JF. Differing mechanisms of exercise flow augmentation at the mitral and aortic valves. Circulation. 1988;77:543-51.

2. Devereux RB, Alonso DR, Lutas EM, Gottlieb GJ, Campo E, Sachs I, et al. Echocardiographic assessment of left ventricular hypertrophy: comparison to necropsy findings. Am J Cardiol. 1986;57:450-8.

3. Eichinger W, Günzinger R, Botzenhardt F, Simmerl D, Gansera B, Kemkes BM. The Mosaic bioprosthesis in the aortic position at five years. J Heart Valve Dis. 2000;9:653-60.

4. Eichinger WB, Botzenhardt F, Günzinger R, Kemkes BM, Sosnowski A, Maïza D, et al. European experience with the Mosaic bioprosthesis. J Thorac Cardiovasc Surg. 2002;124:333-9.

5. Eichinger WB, Botzenhardt F, Günzinger R, Kemkes BM, Bleese N, Sosnowski A, et al. Left ventricular mass regression after aortic valve replacement with the Mosaic bioprosthesis. J Heart Valve Dis. 2002; 11:529-36

6. Botzenhardt F, Gansera B, Kemkes BM. Mid-term hemodynamic and clinical results of the stented porcine Medtronic Mosaic valve in aortic position. Thorac Cardiovasc Surg. 2004;52:34-41.

7. Aupart MR, Sirinelli AL, Diemont FF, Meurisse YA, Dreyfus XB, Marchand MA. The last generation of pericardial valves in the aortic position: ten-year follow-up in 589 patients. Ann Thorac Surg. 1996; 61:615-20

8. Neville PH, Aupart MR, Diemont FF, Sirinelli AL, Lemione EM, Marchand MA. Carpentier-Edwards pericardial bioprosthesis in aortic and mitral position: a twelve year experience. Ann Thorac Surg. 1998;66:143-7.

9. Dellgren G, David TE, Raanani E, Armstrong S, Ivanov J, Rakowski H. Late hemodynamic and clinical outcomes of aortic valve replacement with the Carpentier-Edwards Perimount pericardial bioprosthesis. J Thorac Cardiovasc Surg. 2002;124:146-54.

10. Banbury MK, Cosgrove DM, Thomas JD, Blackstone EH, Rajeswaran J, Okies E, et al. Hemodynamic stability during 17 years of the Carpentier-Edwards aortic pericardial bioprosthesis. Ann Thorac Surg. 2002;73:1460-5

11. Blais C, Dumesnil JG, Baillot R, Simard S, Doyle D, Pibarot P. Impact of valve prosthesis-patient mismatch on short-term mortality after aortic valve replacement. Circulation. 2003;108:983-8.

12. Grunkemeier GI, Bodnar E. Comparative assessment of bioprosthesis durability in the aortic position. J Heart Valve Dis. 1995;4:49-55.

13. Burdon TA, Miller DC, Oyer PE, Mitchell RS, Stinson EB, Starnes VA, et al. Durability of porcine valves at fifteen years in a representative North American patient population. J Thorac Cardiovasc Surg. 1992;103:238-52.

14. Vitale N, Clark S, Ramsden A, Hasan A, Hilton CJ, Holden MP. Clinical and hemodynamic evaluation of small Perimount aortic valves in patients aged 75 years or older. Ann Thorac Surg. 2003;75:35-40.

15. Bortolotti U, Scioti G, Milano A, De Carlo M, Codecasa M, Nardi C, et al. Performance of 21-mm size Perimount aortic bioprosthesis in the elderly. Ann Thorac Surg. 2000;69:47-50.

16. Eichinger WB, Botzenhardt F, Günzinger R, Bleiziffer S, Keithahn A, Bauernschmitt $\mathrm{R}$, et al. The ratio of effective orifice area by patient aortic annulus area- a better way to compare different bioprostheses? 
A prospective randomized comparison of the Mosaic and Perimount bioprosthesis in aortic position. J Heart Valve Dis. 2004;13:382-9.

17. Rahimtola SH. Perspective on valvular heart disease: an update. $J A m$ Coll Cardiol. 1989;14:1-23.

18. Pibarot P, Dumesnil JG, Lemieux M, Cartier P, Metras J, Durand LG. Impact of prosthesis-patient mismatch on hemodynamic and symptomatic status, morbidity, and mortality after aortic valve replacement with a bioprosthetic heart valve. J Heart Valve Dis. 1998;7:211-8.

19. Levy D, Garrison RJ, Savage DD, Kannel WB, Castelli WP. Prognostic implications of echocardiographically determined left ventricular mass in the Framingham heart study. N Engl J Med. 1990;322:1561-6.

20. Sullivan JM, Zwaag RV, El-Zeky F, Ramanathan KB, Mirvis DM. Left ventricular hypertrophy: effect on survival. J Am Coll Cardiol. 1993;22:508-13.

21. Hanayama N, Christakis GT, Mallidi HR, Joyner CD, Fremes SE, Morgan CD, et al. Patient prosthesis mismatch is rare after aortic valve replacement: valve size may be irrelevant. Ann Thorac Surg. 2002;73: $1822-9$.
22. Tasca G, Brunelli F, Cirillo M, Amaducci A, Mhagna Z, Troise G, et al. Mass regression in aortic stenosis after valve replacement with small size pericardial bioprosthesis. Ann Thorac Surg. 2003;76:110713.

23. Khan SS, Siegel RJ, DeRobertis MA, Blanche CE, Kass RM, Cheng $\mathrm{W}$, et al. Regression of hypertrophy after Carpentier-Edwards pericardial aortic valve replacement. Ann Thorac Surg. 2000;69:531-5.

24. De Paulis R, Sommariva L, Colagrande L, De Matteis GM, Fratini S, Tomai F, et al. Regression of left ventricular hypertrophy after aortic valve replacement for aortic stenosis with different valve substitutes. J Thorac Cardiovasc Surg. 1998;116:590-8.

25. Dellgren G, Eriksson MJ, Blange I, Brodin LA, Radegran K, Sylven C. Angiotensin-converting enzyme gene polymorphism influences degree of left ventricular hypertrophy and its regression in patient undergoing operation for aortic stenosis. Am J Cardiol. 1999;84:909-13.

26. Del Rizzo D, Abdoh A, Cartier P, Doty D, Westaby S. Factors affecting left ventricular mass regression after aortic valve replacement. Semin Thorac Cardiovasc Surg. 1999;11:114-20.

Access to The Journal of Thoracic and Cardiovascular Surgery Online is reserved for print subscribers!

Full-text access to The Journal of Thoracic and Cardiovascular Surgery Online is available for all print subscribers. To activate your individual online subscription, please visit The Journal of Thoracic and Cardiovascular Surgery Online, point your browser to http://www.mosby.com/jtcvs, follow the prompts to activate your online access, and follow the instructions. To activate your account, you will need your subscriber account number, which you can find on your mailing label (note: the number of digits in your subscriber account number varies from 6 to 10). See the example below in which the subscriber account number has been circled:

\section{Sample mailing label}

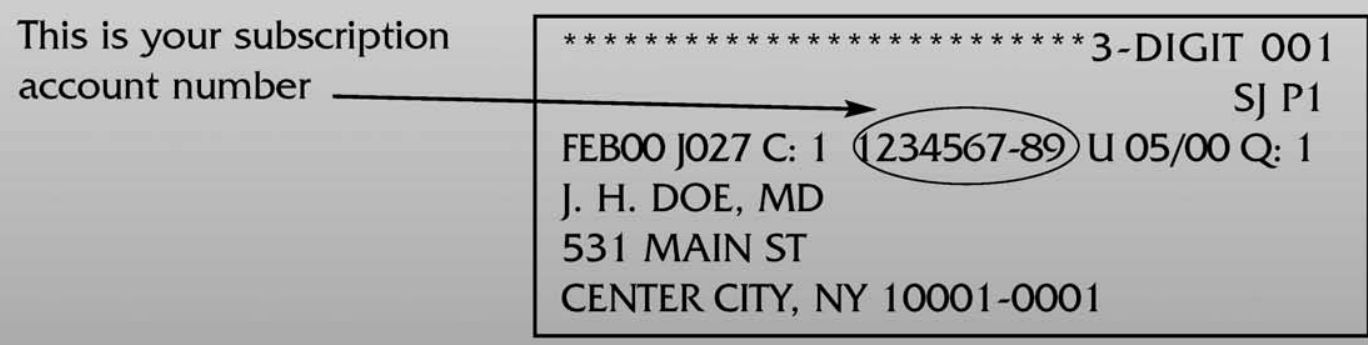

Personal subscriptions to The Journal of Thoracic and Cardiovascular Surgery Online are for individual use only and may not be transferred. Use of The Journal of Thoracic and Cardiovascular Surgery Online is subject to agreement to the terms and conditions as indicated online. 